$\Pi$ индексы оценки степени тяжести (часть 2)

Платонова А. В., Жуков А. С., Хайрутдинов В. Р. ., Самцов А. В.

Военно-медицинская академия им. С.М. Кирова Министерства обороны Российской Федерации

194044, Российская Федерация, г. Санкт-Петербург, ул. Академика Лебедева, д. 6

Псориатическая ониходистрофрия является важным клиническим проявлением псориаза и характеризуется многочисленными симптомами поражения ногтевого ложа и ногтевого матрикса. Для определения степени тяжести псориатической ониходистрофии и терапевтической эфрфективности лекарственных препаратов необходима унифицированная шкала оценки выявляемых признаков. В статье дано описание наиболее распространенных индексов: NAPSI, mNAPSI, target NAPSI, NAS, PNSS, шкала по Baran, N-NAIL. Представлена методология работы с каждым из них, проведена сравнительная характеристика выявляемых симптомов.

Проведенный обзор свидетельствует об отсутствии универсального индекса для оценки степени тяжести псориатической ониходистрофии и определяет необходимость поиска новых диагностических алгоритмов.

Ключевые слова: псориаз, псориатическая ониходистрофия, оценка степени тяжести, индексы, NAPSI

Конфрликт интересов: авторы заявляют об отсутствии потенциального конфрликта интересов, требующего раскрытия в данной статье.

Для цитирования: Платонова А. В., Жуков А. С., Хайрутдинов В. Р., Самцов А. В. Псориатическая ониходистрофрия: индексы оценки степени тяжести (часть 2). Вестник дерматологии и венерологии. 2019;95(1):9-14. https://doi.org/10.25208/0042-4609-2019-95-1-9-14 


\title{
P soriatic onychodystrophy: indices for assessing the severity of psoriatic onychodystrophy (part 2)
}

\author{
Anna V. Platonova, Aleksander S. Zhukov, Vladislav R. Khairutdinov*, Aleksey V. Samtsov
}

S.M. Kirov Military Medical Academy, Ministry of Defence of the Russian Federation

Akademika Lebedeva str., 6, Saint Petersburg, 194044, Russian Federation

Psoriatic onychodystrophy constitutes an important clinical manifestation of psoriasis and is characterised by multiple symptoms of damage to the nail bed and nail matrix. In order to determine the severity of psoriatic onychodystrophy, as well as the therapeutic efficacy of medications, a unified scale is needed.

The article describes the most common indices: NAPSI, mNAPSI, target NAPSI, NAS, PNSS, Baran scale, N-NAIL. In this work, the authors present a methodology for working with each of them, as well as a comparative analysis of detectable symptoms.

The conducted literature review indicates the absence of a universal index for assessing the severity of psoriatic onychodystrophy and determines the need to search for new diagnostic algorithms.

Keywords: psoriasis, psoriatic onychodystrophy, severity assessment, indices, NAPSI

Conflict of interest: the authors state that there is no potential conflict of interest requiring disclosure in this article.

For citation: Platonova A. V., Zhukov A. S., Khairutdinov V. R., Samtsov A. V. Psoriatic onychodystrophy: indices for assessing the severity of psoriatic onychodystrophy (part 2). Vestnik Dermatologii i Venerologii. 2019;95(1):9-14. https://doi.org/10.25208/0042-4609-2019-95-1-9-14 
Ногтевые пластинки играют важную роль в жизни современного человека. Это открытые участки тела, которые придают эстетическую привлекательность кистям и стопам, защищают мягкие ткани ногтевых фраланг от механических повреждений. Больные псориазом с выраженными проявлениями псориатической ониходистрофии часто предъявляют жалобы на эстетический дискомфорт, болезненность кончиков пальцев и затруднения при выполнении руками простейших манипуляций. Поражение ногтей оказывает выраженное негативное влияние на качество жизни, таким пациентам требуется индивидуальный терапевтический подход [1-4].

Изменение ногтевых пластинок при псориазе является значимым прогностическим диагностическим критерием псориатического артрита. Псориатическая ониходистрофия рассматривается многими специалистами как проявление псориаза с «проблемной локализацией», определяющее назначение в тяжелых случаях системной терапии, в том числе генно-инженерных биологических препаратов [2-4].

Для определения степени тяжести поражения и мониторинга динамики состояния ногтевых пластинок необходимы унифицированные методики [4-7]. С этой целью было разработано несколько индексов и шкал, при подсчете которых проводится качественная и количественная оценка определенных диагностических критериев. Учитывая высокую распространенность микотического поражения ногтей стоп, маскирующих изменения ногтевых пластинок при псориазе, оценку степени тяжести псориатической ониходистрофии обычно проводят только на кистях [8, 16].

Наиболее часто используются следующие индексы и шкалы оценки степени тяжести псориатической ониходистрофии:

- Индекс тяжести псориатической ониходистрофрии — NAPSI (Nail Psoriasis Severity Index) [10];

- модифицированный индекс тяжести псориатической ониходистрофрии - mNAPSI (modified NAPSI) [9];

- прицельный индекс тяжести псориатической ониходистрофрии - target NAPSI [15];

- индекс тяжести и площади поражения ногтей NAS (Nail Area Severity) [11];

- шкала оценки тяжести псориатической ониходистрофии - PNSS (The Psoriasis Nail Severity Score) [12];

- шкала оценки тяжести псориатической ониходистрофиии по Baran [13];

- Неймегенский индекс тяжести псориатической ониходистрофии - N-NAIL [14].

Индекс NAPSI был предложен в 2003 году и с тех пор является наиболее используемой методикой определения тяжести псориатической ониходистрофии. При расчете данного индекса каждый ноготь условно делится на 4 квадранта. Каждый квадрант оценивают на наличие симптомов: отдельно поражение ногтевого матрикса (точечные вдавления - симптом «наперстка», лейконихии, красные пятна в лунке, крошение) и ногтевого ложа (симптом «масляного пятна», онихолизис, подногтевой гиперкератоз, продольные геморрагии). При отсутствии перечисленных признаков псориатической ониходистрофии выставляется 0 баллов. Наличие любого симптома вовлечения ногтевого ложа и матрикса в квадранте оценивается в 1 балл для каждого симптома. Для отдельного ногтя общая сумма может достигать 8 баллов: от 0 до 4 баллов - при поражении ногтевого ложа и от 0 до 4 баллов - при изменении ногтевого матрикса. Максимальные значения индекса NAPSI составляют 80 баллов для кистей и 160 баллов для кистей и стоп [10].

Индекс mNAPSI был разработан в целях усовершенствования NAPSI. При его подсчете проводится количественная или качественная оценка 8 признаков псориатической ониходистрофрии на каждом ногте: точечные вдавления, онихолизис, симптом «масляного пятна», крошение, лейконихии, продольные геморрагии, подногтевой гиперкератоз и красные пятна в лунке. Точечные вдавления, онихолизис, симптом «масляного пятна» и крошение оценивают от 0 до 3 баллов в зависимости от степени выраженности проявлений. Учитывается количество точечных вдавлений, при их отсутствии выставляется 0 баллов, от 1 до 10 вдавлений - 1 балл, от 11 до 49 - 2 балла, 50 и более - 3 балла. Крошение ногтевой пластинки определяют по площади поражения: отсутствие - 0 баллов, поражение от 1 до $25 \%$ поверхности - 1 балл, от 26 до $50 \%-2$ балла, более $50 \%-3$ балла. Онихолизис и симптом «масляного пятна» оцениваются вместе: отсутствие этих проявлений - 0 баллов, поражение до $10 \%$ площади ногтя 1 балл, от 10 до $30 \%-2$ балла, $30 \%$ и более - 3 балла. Лейконихии, продольные геморрагии, подногтевой гиперкератоз и красные пятна в лунке регистрируются только по наличию или их отсутствию в 1 или 0 баллов за каждый соответственно. Суммарно для одного пальца можно получить 13 баллов. Наибольшее значение индекса mNAPSI для кистей - 130 баллов [9].

TargetNAPSI позволяет оценить только один наиболее пораженный ноготь на кистях и стопах по 8 показателям: точечные вдавления, лейконихии, крошение, красные пятна в лунке, продольные геморрагии, онихолизис, симптом «масляного пятна», подногтевой гиперкератоз. Каждый симптом оценивается от 0 до 3 баллов. Отсутствие признака - 0 баллов, незначительные проявления - 1 балл, умеренные - 2 балла, выраженные 3 балла. Максимальная сумма - 24 балла [15].

Индекс NAS оценивается по 4 симптомам: точечные вдавления (учитывается отдельно площадь поражения и количество углублений), онихолизис, симптом «масляного пятна», подногтевой гиперкератоз. Выставляется от 0 до 4 баллов за каждый признак. При выявлении точечных вдавлений, онихолизиса и симптома «масляных пятен» определяется площадь пораженного участка ногтя: отсутствие поражения - 0 баллов, поражение до $25 \%$ поверхности - 1 балл, от 25 до $50 \%-2$ балла, от 50 до $75 \%$ - 3 балла, $75 \%$ и более - 4 балла. Точечные вдавления на одной ногтевой пластинке в количестве от 1 до 15 оценивают в 1 балл, от 15 до $30-$ 2 балла, от 30 до $45-3$ балла, 45 и более - 4 балла. Подногтевой гиперкератоз измеряют по толщине гиперкератотических масс под дистальным краем ногтя: отсутствие признака - 0 баллов, подногтевой гиперкератоз толщиной до 1 мм - 1 балл, от 1 до 2 мм - 2 балла, от 2 до 3 мм - 3 балла, более 3 мм - 4 балла. Максимальное значение - 20 баллов для одной ногтевой пластинки и 200 баллов для 10 пальцев [11].

Индекс PNSS позволяет определить степень тяжести поражения ногтевых пластинок по 4 симптомам: точечные вдавления, крошение ногтя, подногтевой гиперкератоз, онихолизис. Каждое проявление оценивают 
по его наличию или отсутствию -1 или 0 баллов соответственно. Суммарно можно получить 40 баллов для 10 пальцев [12].

Шкала оценки тяжести псориатической ониходистрофии по Baran включает 4 симптома: точечные вдавления, подногтевой гиперкератоз, онихолизис и линии Бо (поперечные борозды). При выявлении до 10 точечных вдавлений на одном ногте выставляется 1 балл, от 10 до $20-2$ балла, 20 и более - 3 балла. Выраженность подногтевого гиперкератоза определяют по толщине гиперкератотических масс под дистальным краем ногтевой пластинки: до 2 мм - 1 балл, от 2 до 3 мм 2 балла, более 3 мм - 3 балла. Наличие 1 поперечной борозды (линии Бо) оценивается в 1 балл, 2-3 борозд 2 балла, более $3-3$ балла. Для определения площади онихолизиса авторы рекомендуют делить ногтевую пластинку на 8 частей, каждая из которых будет соответствовать 12,5 \% поверхности ногтя. При поражении до $25 \%$ ногтевой пластинки выставляется 1 балл, от 25 до $50 \%$ - 2 балла, больше $50 \%$ - 3 балла. Суммарно можно получить до 12 баллов для одного и до 120 баллов для 10 ногтей соответственно [13].

Индекс N-NAIL был разработан с учетом результатов сравнительной характеристики представленных выше индексов. N-NAIL включает оценку 6 симптомов поражения ногтевых пластинок: линии Бо, точечные вдавления, крошение ногтя, онихолизис / симптом «масляного пятна» и подногтевой гиперкератоз. Каждый симптом оценивается по 3-балльной системе. При наличии 1 поперечной борозды (линии Бо) выставляют 1 балл, 2-3 борозд - 2 балла, более 3 - 3 балла. Определяют степень выраженности точечных вдавлений и крошение ногтя: отсутствие признака - 0 баллов, незначительные проявления - 1 балл, умеренные - 2 балла, значительные - 3 балла. Онихолизис и симптом «масляного пятна» оценивают по площади поражений ногтевой пластинки. Отсутствие онихолизиса и «масляных пятен» - 0 баллов, поражение до $25 \%$ ногтя - 1 балл, от 25 до $50 \%$ - 2 балла, более $50 \%-$ 3 балла. Подногтевой гиперкератоз измеряют по толщине гиперкератотических масс под дистальным краем ногтевой пластинки: отсутствие симптома - 0 баллов, до 1 мм - 1 балл, от 1 до 3 мм - 2 балла, более 3 мм -
3 балла. Максимальное значение данного индекса для 10 пальцев - 150.

В настоящее время отсутствует общепринятая система оценки степени тяжести псориатической ониходистрофии. Существующие индексы и шкалы отличаются методикой подсчета (сложностью и субъективностью), набором определяемых клинических симптомов, применением качественной и/или количественной оценки изменений (табл. 1).

Индекс NAPSI наиболее часто используется в практической деятельности для оценки тяжести псориатической ониходистрофии. Однако он дает информацию исключительно о наличии или отсутствии симптомов поражения ногтевого ложа и матрикса без определения степени выраженности проявлений. Используя этот индекс, трудно отследить динамику в состоянии ногтей. В перечень определяемых признаков псориатической ониходистрофрии включено крайне редкое проявление поражения ногтевого матрикса - красные пятна в лунке и низкоспецифичный симптом - лейконихии. В то же время при подсчете индекса не учитывается такой признак, как линии Бо, который нередко встречается у больных псориазом, что снижает объективность полученных данных. Поражение ногтей часто носит асимметричный характер, при этом деление ногтевой пластинки на равные квадранты приводит к уменьшению итоговых значений NAPSI. Важно отметить, что NAPSI - единственный стандартизированный индекс, прошедший валидацию.

Использование индекса mNAPSI позволяет получить более объективные данные по сравнению с NAPSI. B mNAPSI оценивается не только номинальное наличие или отсутствие ряда признаков, но и количественно определяется выраженность четырех симптомов псориатической ониходистрофии: точечных вдавлений, крошения, симптома «масляных пятен» и онихолизиса. Методика подсчета данного индекса более сложная, но она позволяет оценивать состояние ногтевых пластинок в динамике.

Индекс targetNAPSI достаточно прост в использовании. В этом индексе определяются те же симптомы, что и в NAPSI, но выполняется не качественная, а количественная оценка. K недостаткам targetNAPSI следует

Таблица 1. Сравнительная характеристика индексов оценки степени тяжести псориатической ониходистрофии

Table 1. Comparative analysis of indices for assessing the severity of psoriatic onychodystrophy

\begin{tabular}{|c|c|c|c|c|c|c|c|c|c|c|c|c|c|c|}
\hline \multirow{2}{*}{ Симптомы } & \multicolumn{2}{|c|}{ NAPSI } & \multicolumn{2}{|c|}{ mNAPSI } & \multicolumn{2}{|c|}{ Target NAPSI } & \multicolumn{2}{|c|}{ Baran } & \multicolumn{2}{|c|}{ PNSS } & \multicolumn{2}{|c|}{ NAS } & \multicolumn{2}{|c|}{ N-Nail } \\
\hline & 1 & 2 & 1 & 2 & 1 & 2 & 1 & 2 & 1 & 2 & 1 & 2 & 1 & 2 \\
\hline Онихолизис & + & - & - & + & - & + & - & + & + & - & - & + & - & + \\
\hline Симптом «масляного пятна» & + & - & - & + & - & + & - & - & - & - & - & + & - & + \\
\hline Точечные вдавления & + & - & - & + & - & + & - & + & + & - & - & + & - & + \\
\hline Подногтевой гиперкератоз & + & - & + & - & - & + & - & + & + & - & - & + & - & + \\
\hline Красные пятна в лунке & + & - & + & - & - & + & - & - & - & - & - & - & - & - \\
\hline Линии Бо & - & - & - & - & - & - & - & + & - & - & - & - & - & + \\
\hline Крошение & + & - & - & + & - & + & - & - & + & - & - & - & - & + \\
\hline Лейконихия & + & - & + & - & - & + & - & - & - & - & - & - & - & - \\
\hline Продольные геморрагии & + & - & + & - & - & + & - & - & - & - & - & - & - & - \\
\hline
\end{tabular}


отнести высокую субъективность методики вследствие отсутствия четкой градации степеней тяжести проявлений, что может существенно влиять на итоговые значения показателя. Оценка только одной ногтевой пластинки, которую выбирает специалист, не отражает целостной клинической картины и не позволяет судить о состоянии ногтей на других пальцах. С помощью индекса targetNAPSI затруднительно отслеживать проявления псориатической ониходистрофрии в процессе терапии.

В индексе NAS тяжесть псориатической ониходистрофии оценивают по пяти показателям, используется всего четыре наиболее часто встречаемых проявления псориатической ониходистрофии из двенадцати возможных. Методика подсчета для каждого симптома количественная, все признаки имеют точные критерии, определяющие количество начисляемых баллов. Необходимо отметить, что симптом «масляного пятна» и онихолизис являются проявлением одного и того же патологического процесса на разных этапах. В некоторых случаях бывает достаточно трудно определить границы между этими поражениями в области дистальных отделов ногтевого ложа.

Метод подсчета индекса PNSS является наиболее простым и быстрым из рассмотренных. В индексе PNSS, как и NAPSI, осуществляется только качественная оценка симптомов псориатической ониходистрофии. В связи с этим PNSS неудобен для изучения динамики состояния ногтевых пластинок на фоне проводимого лечения. Выявлена высокая корреляция между этим индексом и оценкой PGA (Physician global assessment - общая оценка врачом) больных псориазом [14].
В шкале оценки тяжести псориатической ониходистрофии по Baran используется количественная методика, имеется четкая градация степеней выраженности признаков. В этой шкале учитывается наличие линий Бо, но не оценивается часто встречаемый у больных псориазом симптом «масляного пятна».

Индекс N-NAIL позволяет наиболее полно и объективно определить степень тяжести поражения ногтей при псориазе. Этот индекс рассчитывается на основе количественной оценки наиболее часто встречающихся проявлений псориатической ониходистрофиии. Для всех признаков поражения ногтевых пластинок установлены точные границы, соответствующие определенному количеству баллов. Симптомы «масляного пятна» и онихолизис оценивают вместе, что повышает точность метода. Использование индекса N-NAIL позволяет получать более корректные данные о степени тяжести псориатической ониходистрофии и изменении состояния ногтевых пластинок в процессе терапии. К недостаткам метода стоит отнести сложность подсчета и значительные затраты по времени при определении индекса N-NAIL.

Обзор литературы свидетельствует об отсутствии единого удобного и объективного индекса оценки степени тяжести псориатической ониходистрофии. Ближе всех, на наш взгляд, к «универсальному» методу находится индекс N-NAIL, но он не валидирован в Российской Федерации. В настоящее время существует потребность в разработке новых алгоритмов, позволяющих оценить тяжесть поражения ногтевых пластинок у больных псориазом, исследовать терапевтическую эфффективность лекарственных препаратов в лечении псориатической ониходистрофии.

\section{Литература/References}

1. Gibbs S. Skin disease and socioeconomic conditions in rural Africa: Tanzania. Int J Dermatol. 1996;35(9):633-642.

2. Danielsen K., Olsen A. O., Wilsgaard T., Furberg A. S. Is the prevalence of psoriasis increasing? A 30-year follow-up of a population based cohort. Br J Dermatol. 2013;168:1303-1310.

3. Jiaravuthisan M. M., Sasseville D., Vender R. B. et al. Psoriasis of the nail: anatomy, pathology, clinical presentation, and a review of the literature on therapy. J Am Acad Dermatol. 2007;57(1):1-27.

4. Crowley J., Weinberg J., Wu J. et al. Treatment of nail psoriasis: best practice recommendations from the Medical Board of the National Psoriasis Foundation. JAMA Dermatol. 2015;151:87-94.

5. Reich K. Approach to managing patients with nail psoriasis. Eur Acad Dermatol Venereol. 2009;23(1):15-21.

6. Armesto S., Esteve A., Coto-Segura P. et al. Nail psoriasis in individuals with psoriasis vulgaris: a study of 661 patients. Actas Dermosifiliogr. 2011;102:365-372

7. Parlo-Castello V., Pardo 0. A. Disease of the nails. Springfield: Thomas, 1960. $48 \mathrm{p}$.

8. Samman P. D. The nails in Disease. London: Heinemann, 1978. $238 p$.
9. Cassell S. E., Bieber J. D., Rich P. et al. The modified nail psoriasis severity index: validation of an instrument to assess psoriatic nail involvement in patients with psoriatic arthritis. J Rheumatol. 2007;3:123-132.

10. Rich P., Scher R. K. Nail psoriasis severity index: a useful tool for evaluation of nail psoriasis. J Am Acad Dermatol. 2003;49(2):206-212.

11. Jong E. M., Menke H. E., van de Praag M. C., van De Kerkhof P. C. Dystrophic psoriatic fingernails treated with $1 \% 5$-fluorouracil in a nail penetration-enhancing vehicle: a double-blind study. Dermatology. 1999;199:313-321.

12. Jones S. M., Armas J. B., Cohen M. G. et al. Psoriatic arthritis: outcome of disease subsets and relationship of joint disease to nail and skin disease. Br J Rheumatol.1994;33:834-843.

13. Baran R. L. A nail psoriasis severity index. $\mathrm{Br} J$ Dermatol. 2004;150:568-577.

14. Karlijn M. G., Klaassen M. D., Peter C. M. et al. Scoring nail psoriasis. J Am Acad Dermatol. 2014;6:1061-1066.

15. Parrish C. A., Sobera J. O., Elewski B. E. Modification of the nail psoriasis severity index. J Am Acad Dermatol. 2005;53:745-751.

16. Klaassen K. M. G., Dulak M. G., van de Kerkhof P. C. M., Pasch M. C. The prevalence of onychomycosis in psoriatic patients: systematic review. J Eur Acad Dermatol Venereol. 2014;28(5):533-574. 


\section{Информация об авторах}

Анна Вячеславовна Платонова - аспирант кафедры кожных и венерических болезней Военно-медицинской академии им. С.М. Кирова Министерства обороны Российской Федерации; e-mail: platonova1105@gmail.com

Александр Сергеевич Жуков - к.м.н., докторант кафедры кожных и венерических болезней Военно-медицинской академии им. С.М. Кирова Министерства обороны Российской Федерации; e-mail: doctor-vma@mail.ru

Владислав Ринатович Хайрутдинов ${ }^{*}$ - д.м.н., доцент, доцент кафедры кожных и венерических болезней Военно-медицинской академии им. С.М. Кирова Министерства обороны Российской Федерации; е-mail: haric03@list.ru

Алексей Викторович Самцов - Д.м.н., профессор, заведующий кафедрой кожных и венерических болезней Военно-медицинской академии им. С.М. Кирова Министерства обороны Российской Федерации; e-mail: avsamtsov@mail.ru

\section{Information about the authors}

Anna V. Platonova - PhD researcher, Department of Skin and Venereal Diseases, S.M. Kirov Military Medical Academy, Ministry of Defence of the Russian Federation; e-mail: platonova1105@gmail.com

Aleksander S. Zhukov - Cand. Sci. (Med.), Doctoral Candidate, Department of Skin and Venereal Diseases, S.M. Kirov Military Medical Academy, Ministry of Defence of the Russian Federation; e-mail: doctor-vma@mail.ru

Vladislav R. Khairutdinov* - Dr. Sci. (Med.), Associate Professor, Department of Skin and Venereal Diseases, S.M. Kirov Military Medical Academy, Ministry of Defence of the Russian Federation; e-mail: haric03@list.ru

Aleksey V. Samtsov - Dr. Sci. (Med.), Prof., Departmental Head, Department of Skin and Venereal Diseases, S.M. Kirov Military Medical Academy, Ministry of Defence of the Russian Federation; e-mail: avsamtsov@mail.ru

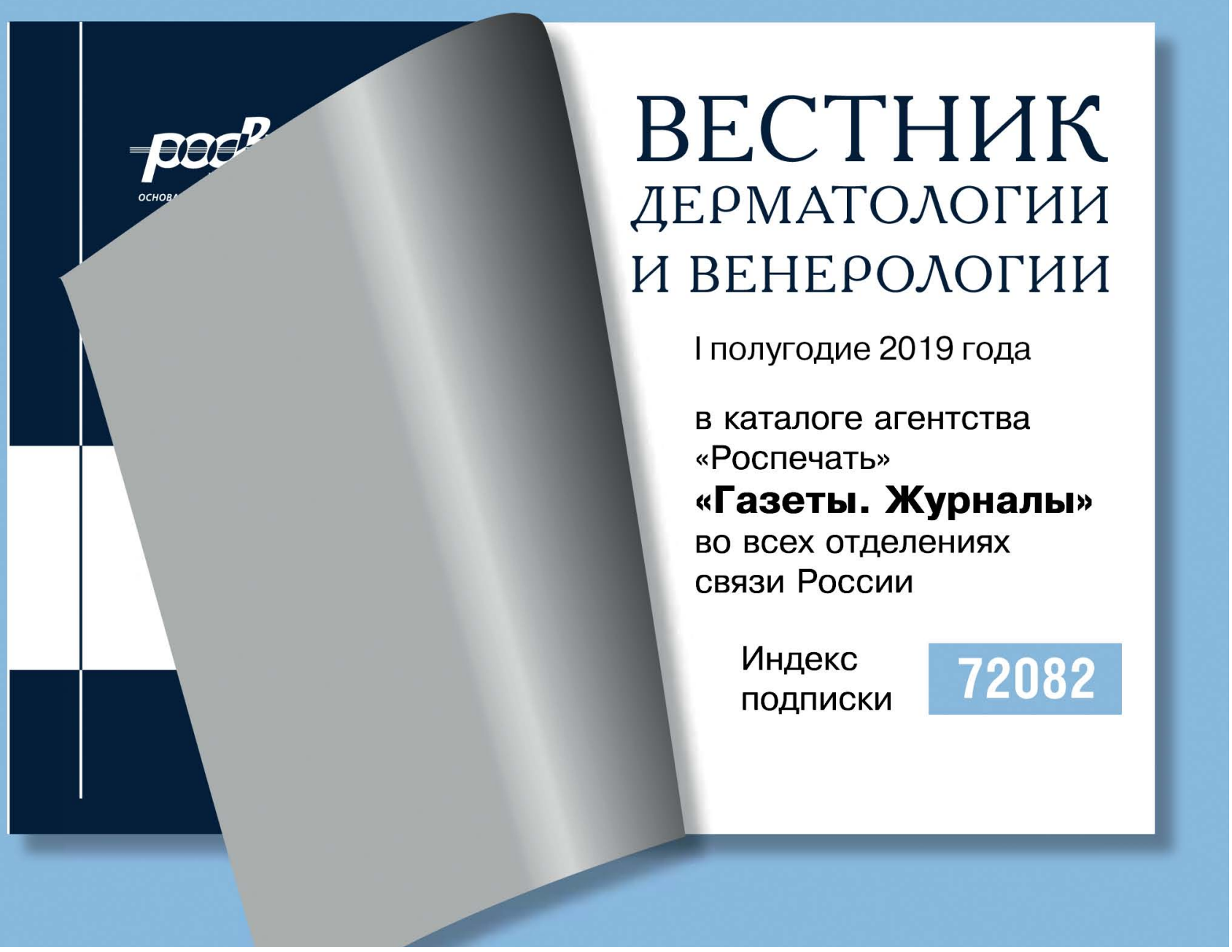

